OPEN ACCESS

Edited by:

Songwen Tan,

Central South University, China

Reviewed by:

Wenjun Gu,

Shanghai Jiao Tong University School of Medicine, China

Lihu Xie,

University of South China, China

*Correspondence:

Xiaoqiang Wei

Weixiaoqiang1998@smmu.edu.cn

${ }^{\dagger}$ These authors share first authorship

Specialty section:

This article was submitted to Visceral Surgery,

a section of the journal

Frontiers in Surgery

Received: 29 December 2021 Accepted: 24 January 2022

Published: 22 February 2022

Citation:

Guo $F$, Tang $H$ and Wei $X$ (2022) Comparison of Different Blood Transfusion Methods in Patients Undergoing Cesarean Section.

Front. Surg. 9:844984.

doi: 10.3389/fsurg.2022.844984

\section{Comparison of Different Blood Transfusion Methods in Patients Undergoing Cesarean Section}

\author{
$\mathrm{Fei} \mathrm{Guo}^{\dagger}$, Heshan Tang ${ }^{\dagger}$ and Xiaoqiang Wei ${ }^{*}$ \\ Department of Blood Transfusion, The First Affiliated Hospital of Naval Military Medical University, Shanghai, China
}

Purpose: To compare the effect of allogeneic transfusion and acute normovolemic hemodilution (ANH) autologous transfusion in patients undergoing cesarean section.

Methods: Patients who underwent cesarean section and received blood transfusion therapy from February 2019 to July 2021 in our hospital were observed and divided into the allogeneic group $(n=55)$ who received allogeneic transfusion therapy and the autologous group $(n=55)$ who received $\mathrm{ANH}$ autologous transfusion therapy according to the mode of transfusion. Observations included vital signs [heart rate $(\mathrm{HR})$, mean arterial pressure (MAP), stroke volume variation (SW)], blood routine [red blood cells (RBC), platelets (PLT), hematocrit $(\mathrm{HCT})$, hemoglobin $(\mathrm{Hb})]$, T-cell subsets $\left(\mathrm{CD} 4^{+}, \mathrm{CD}^{+}\right.$, $\mathrm{CD}^{+} / \mathrm{CD}^{+}$), immunoglobulins (IgA, $\operatorname{lgM}$, IgG), inflammatory factors [C-reactive protein (CRP), tumor necrosis factor (TNF)- $\alpha$, interleukin (IL)-6], and adverse effects were counted in both groups.

Results: There was no statistical significance in the intra-group and inter-group comparisons of HR, MAP, and SW between the two groups before transfusion and transfusion for 10 min $(P>0.05)$. $5 d$ after operation, the RBC, PLT, HCT, and $\mathrm{Hb}$ of the allogeneic group were lower than those before operation, and the autologous group was higher than that of the allogeneic group $(P<0.05)$. $5 d$ after operation, the CRP, TNF- $\alpha$, and IL-6 of the allogeneic group were higher than those before operation, and the autologous group was lower than that of the allogeneic group $(P<0.05)$. $5 d$ after operation, the $\mathrm{CD} 4^{+}, \mathrm{CD} 4^{+} / \mathrm{CD} 8^{+}$of the allogeneic group were lower than before operation, and the $\mathrm{CD} 8^{+}$was higher than before operation. The $\mathrm{CD} 4^{+}$and $\mathrm{CD} 4^{+} / \mathrm{CD} 8^{+}$ of the autologous group were higher than that of the allogeneic group, and $\mathrm{CD} 8^{+}$was lower than that of the allogeneic group $(P<0.05)$. $5 \mathrm{~d}$ after operation, the $\lg \mathrm{A}$, IgG, and IgM of the allogeneic group were lower than those before operation, and the autologous group was higher than that of the allogeneic group $(P<0.05)$. During blood transfusion, there was no significant difference in the adverse reaction rate between the two groups $(P>0.05)$. 
Conclusion: Both allogeneic transfusion and $\mathrm{ANH}$ autologous transfusion have little effect on the vital signs of patients undergoing cesarean section, but $\mathrm{ANH}$ autologous transfusion is more helpful to the stability of blood routine, T-cell subsets, immunoglobulin, and inflammation levels after surgery, which is a safe and effective way of blood transfusion.

Keywords: cesarean section, allogeneic transfusion, acute normovolemic hemodilution, autologous transfusion, application effect

\section{INTRODUCTION}

Cesarean section is an important midwifery procedure in the field of obstetrics. It is suitable for cases where the fetus cannot be delivered from the vagina normally, such as cephalopelvic error, birth canal abnormalities, fetal distress, fetal position error, umbilical cord prolapse, history of cesarean section, multiple births, etc. $(1,2)$. Placenta praevia and placental abruption are common complications of cesarean section, which can exacerbate the incidence of perinatal hemorrhage in cesarean section, and the incidence is much higher than that of natural delivery, therefore, in obstetric surgery, the blood transfusion rate of cesarean section $0.77 \%$ is higher than natural delivery $0.23 \%(3,4)$. Preoperative blood preparation is an important preoperative preparation for cesarean section. It can effectively reduce the risk of disseminated intravascular coagulation (DIC), shock and even death in patients with cesarean section bleeding. Therefore, it is beneficial to improve the uterine retention rate and survival rate of pregnant women. For patients with large blood loss during cesarean section, urgent blood transfusion is often required in clinic, currently, allogeneic blood transfusion is mainly used, but it is associated with postoperative infection, immunosuppression and a poor prognosis (5). Acute normovolemic hemodilutio (ANH) autologous transfusion is an autologous blood transfusion method in which autologous blood is drawn preoperatively and supplemented with an equal volume of crystal or colloidal fluid, and the patient's blood loss is combined during the operation to return the autologous blood (6).

The acute normovolemic hemodilutio (ANH) autologous transfusion is a form of autotransfusion in which autologous blood is drawn preoperatively and replenished with an equal volume of crystalloid or colloidal fluid, and then returned autologous blood intraoperatively according to the amount of blood lost by the patient (6). It can effectively reduce the hematocrit (HCT), reduce the loss of blood elements during bleeding, improve the body's tolerance after hemodilution, and shorten the time of ischemia and hypoxia in patients through blood dilution, which is a blood conservation technique that can reduce the risk of anesthesia and surgery and provide fresh

TABLE 1 | Comparison of patients' general conditions ( $n, M \pm S D, \%)$.

\begin{tabular}{|c|c|c|c|c|}
\hline Indexs & Allogeneic group $(n=55)$ & Autologous group $(n=55)$ & $t / \chi^{2}$ value & $P$ value \\
\hline Age (years old) & $28.02 \pm 3.11$ & $28.76 \pm 2.98$ & 1.274 & 0.205 \\
\hline Gestational week (weeks) & $36.54 \pm 0.59$ & $36.62 \pm 0.61$ & 0.699 & 0.486 \\
\hline Body mass index $\left(\mathrm{kg} / \mathrm{cm}^{2}\right)$ & $26.85 \pm 3.24$ & $27.03 \pm 3.26$ & 0.290 & 0.772 \\
\hline Operative time (h) & $1.57 \pm 0.83$ & $1.61 \pm 0.79$ & 0.259 & 0.796 \\
\hline Blood loss (mL) & $953.25 \pm 26.01$ & $956.24 \pm 25.47$ & 0.609 & 0.544 \\
\hline$\geq 2$ & $31(56.36)$ & $29(52.73)$ & & \\
\hline History of cesarean section (cases) & & & 0.042 & 0.838 \\
\hline No & $37(67.27)$ & $38(69.09)$ & & \\
\hline Yes & $18(32.73)$ & $17(30.91)$ & & \\
\hline ASA classification (cases) & & & 0.146 & 0.702 \\
\hline Placenta previa & 38 (69.09) & $39(70.91)$ & & \\
\hline Placental abruption & $5(9.09)$ & $4(7.27)$ & & \\
\hline Placental implantation & $3(5.46)$ & $4(7.27)$ & & \\
\hline Others & $9(16.36)$ & $8(14.55)$ & & \\
\hline
\end{tabular}


A

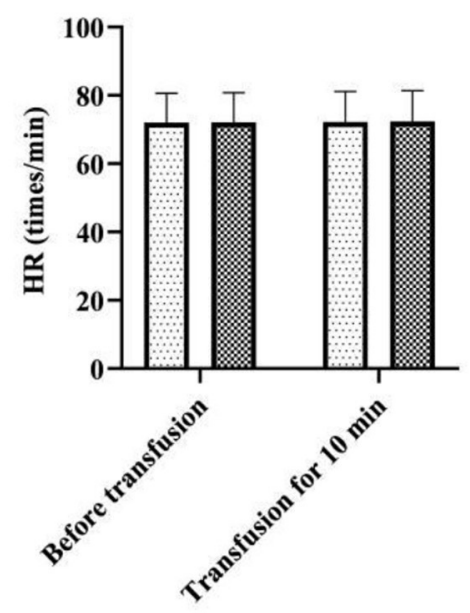

C

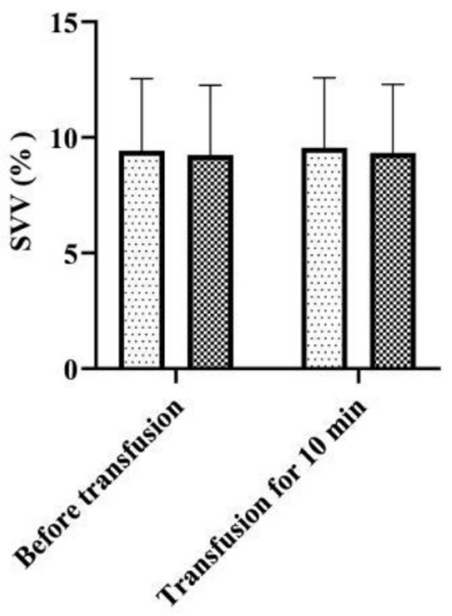

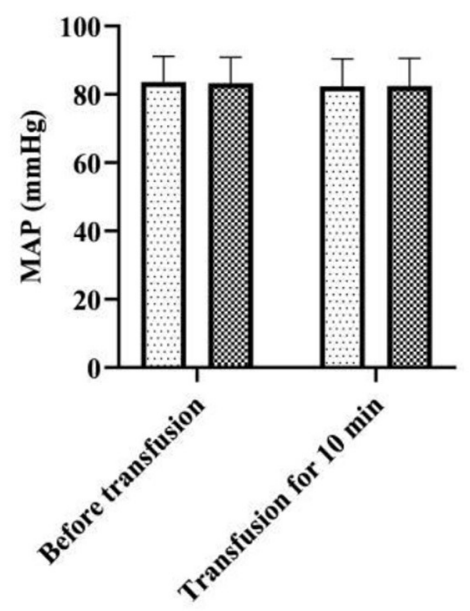

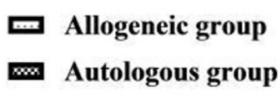

Allogeneic group

Autologous group
Allogeneic group

Autologous group

FIGURE 1 | Effect of different blood transfusion methods on patients' vital signs. (A) HR, (B) MAP, and (C) SW.

whole blood to the patient (7). It has been widely used in major surgeries such as orthopedics, oncology and neurosurgery, but there are very few applications and related reports in the field of obstetrics $(8,9)$. This study compares the application effect of allogeneic transfusion and $\mathrm{ANH}$ autologous transfusion in patients undergoing cesarean section, aiming to explore the effectiveness and safety of ANH autologous transfusion in patients undergoing cesarean section.

\section{MATERIALS AND METHODS}

\section{Research Object}

Patients who underwent cesarean section and received blood transfusion from February 2019 to July 2021 in our hospital were used as observation subjects. Inclusion criteria: age 2035 years old; proposed cesarean section; American Society of Anesthesiologists (ASA) classification II-III (10); normal liver and kidney function, normal cardiopulmonary function; normal four items before transfusion; normal coagulation function; preoperative platelet (PLT) $>100 \times 10^{9} / \mathrm{L}$, HCT $>33 \%$, hemoglobin $(\mathrm{Hb})>110 \mathrm{~g} / \mathrm{L}$ (11); patients or her family had signed the informed consent. Exclusion criteria: people undergoing allogeneic and autologous transfusion at the same time; people who had a history of heart disease or tumor disease; people who had a history of neurological or psychiatric disease; people with immune system diseases; people with systemic acute and chronic infections; People with cognitive and communication impairments. They were divided into the allogeneic group $(n=55)$ receiving allogeneic transfusion therapy and the autologous group $(n=55)$ receiving $\mathrm{ANH}$ autologous transfusion therapy according to the mode of blood transfusion. There was no significant difference between the two groups in terms of age, gestational weeks and other general conditions, 
A

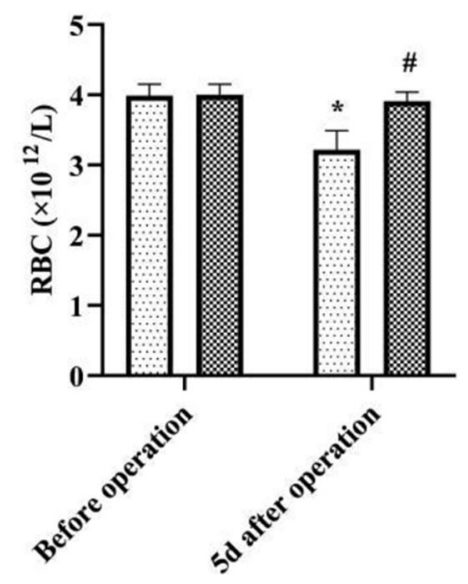

C

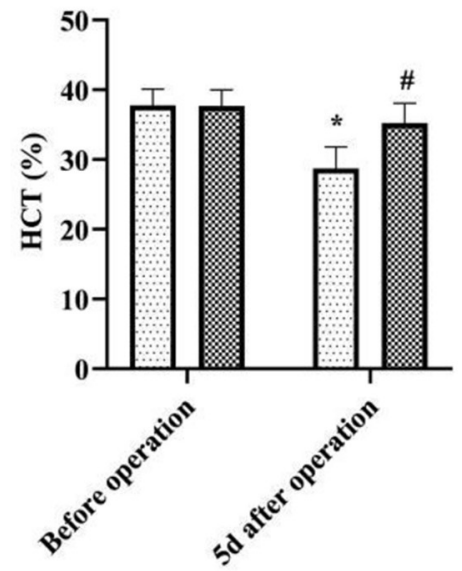

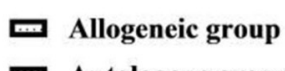

Autologous group
B

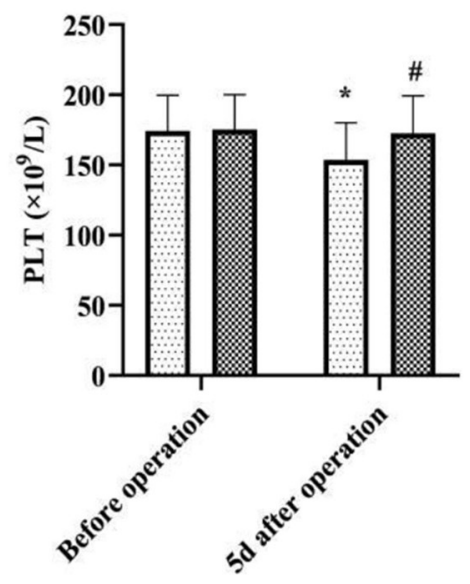

D

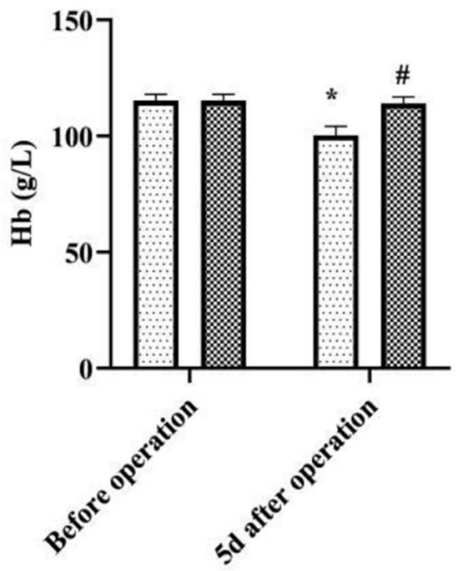

. Allogeneic group

matologous group

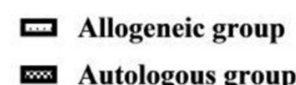

Autologous group

(A) RBC, (B) PLT, (C) HCT, and (D) Hb. Compared with the same group before

FIGURE 2 | Effect of different blood transfusion methods on patients' blood routine. (A) operation, ${ }^{\star} P<0.05$; compared with allogeneic group $5 \mathrm{~d}$ after operation, ${ }^{\#} P<0.05$.

which were comparable, which were comparable $(P>0.05)$ (Table 1).

\section{Research Methods}

Patients in both groups underwent cesarean section and general anesthesia was induced intraoperatively. On this basis, the allogeneic group received allogeneic transfusion therapy, i.e., when $\mathrm{HCT}<24 \%$ or $\mathrm{Hb}<80 \mathrm{~g} / \mathrm{L}$, stock blood was taken for transfusion perfusion according to the amount of blood lost by the patient. The autologous group received ANH autologous transfusion therapy, i.e., radial artery and right internal jugular vein puncture placement were performed after induction of anesthesia and before the start of surgery. Preoperatively, according to the patient's intraoperative bleeding prediction, the CZK-IB microcomputer liquid sampling controller (purchased from Zhengzhou Feilong Medical Equipment Co., Ltd.) was used to collect $300-420 \mathrm{~mL}$ of autologous blood through the radial artery and stored in a blood storage bag and treated with light shielding and freshness. An equal volume of $6 \%$ hydroxyethyl starch (HES) 130/0.4 (purchased from Shandong Hualu Pharmaceutical Co., Ltd., approval number H37022757) was then infused via the internal jugular vein. autologous blood was transfused at the end of the main intraoperative step or when the bleeding volume was $\geq 1,000 \mathrm{~mL}$ or $\mathrm{Hb}$ was $\leq 100 \mathrm{~g} / \mathrm{L}$.

\section{Observation Index}

(1) Vital signs: heart rate (HR), mean arterial pressure (MAP), and stroke volume variation (SVV) were monitored before transfusion and transfusion for $10 \mathrm{~min}$ by a PICCO monitor (purchased from Beijing Shimao Medical Equipment Trading Co., Ltd.). 


\section{A}

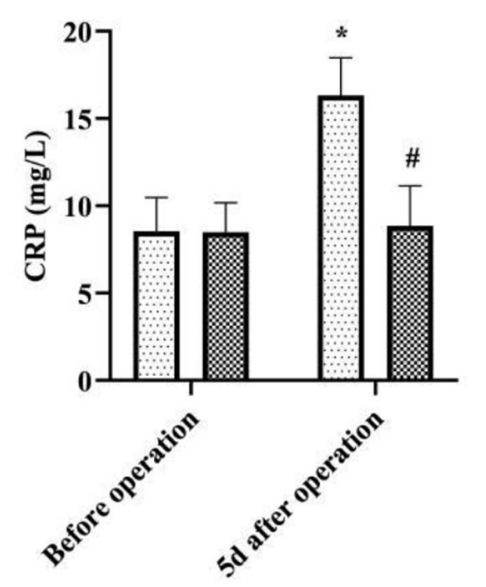

C

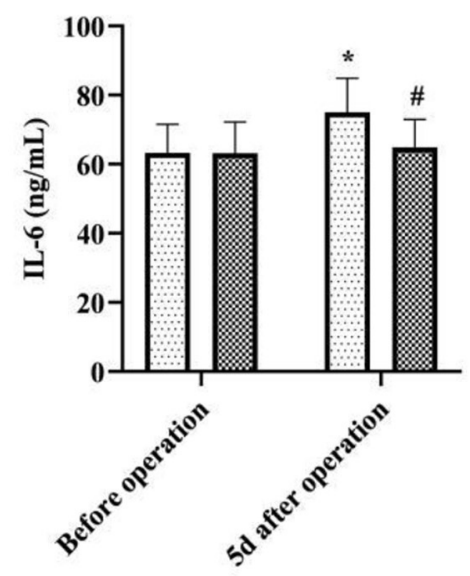

B

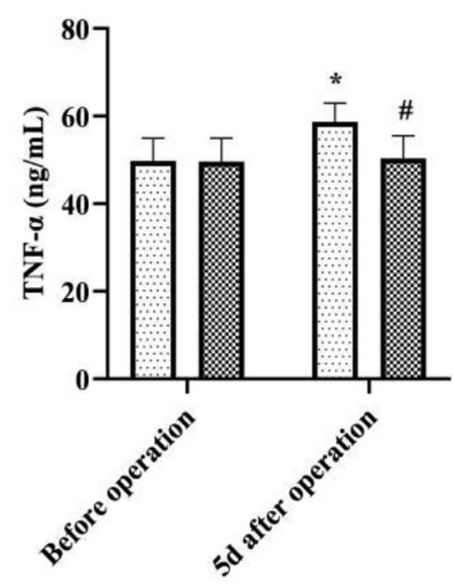

Allogeneic group Autologous group

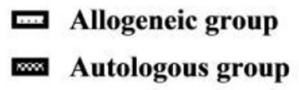

Autologous group
Allogeneic group

Autologous group

FIGURE 3 | Effect of different blood transfusion methods on patients' inflammatory factors. (A) CRP, (B) TNF- $\alpha$, and (C) IL-6. Compared with the same group before operation, ${ }^{\star} P<0.05$; compared with allogeneic group $5 \mathrm{~d}$ after operation, ${ }^{\#} P<0.05$.

(2) Blood routine: The red blood cell (RBC), PLT, HCT and $\mathrm{Hb}$ levels were measured before and $5 \mathrm{~d}$ after surgery by MAXM automatic hematology analyzer (purchased from Beckman Coulter, Inc.).

(3) T-cell subsets: The $\mathrm{CD} 4^{+}, \mathrm{CD}^{+}, \mathrm{CD} 4^{+} / \mathrm{CD} 8^{+}$levels were measured before and $5 \mathrm{~d}$ after surgery by a Cytomics FC500 flow cytometer (purchased from Beckman Coulter, Inc.).

(4) Immunoglobulins: The IgA, IgM, and IgG levels were measured before and $5 \mathrm{~d}$ after surgery by enzyme-linked immunosorbent assay (The kit was purchased from Roche).

(5) Inflammatory factors: C-reactive protein (CRP), tumor necrosis factor (TNF)- $\alpha$ and interleukin (IL)6 levels were measured before and $5 \mathrm{~d}$ after surgery by enzyme-linked immunosorbent assay (The kit was purchased from Shanghai Sange Biotechnology Co., Ltd.).
(6) Adverse reaction rate: Allergy, fever, hemolysis and other adverse reactions occurred during blood transfusion in the two groups were counted.

\section{Statistical Methods}

SPSS 22.0 software was applied, and the measurement data were expressed as mean \pm standard deviation $(M \pm S D)$ and compared by $t$-test. Count data were expressed as ratio, and the $\chi^{2}$ test was used for comparison. $P<0.05$ was considered statistically significant.

\section{RESULTS}

\section{Effect of Different Blood Transfusion Methods on Patients' Vital Signs}

There was no statistical significance in the intra-group and intergroup comparisons of HR, MAP, and SVV between the two 
A

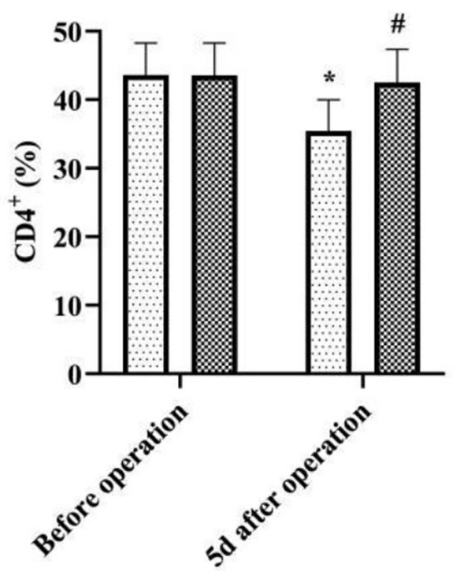

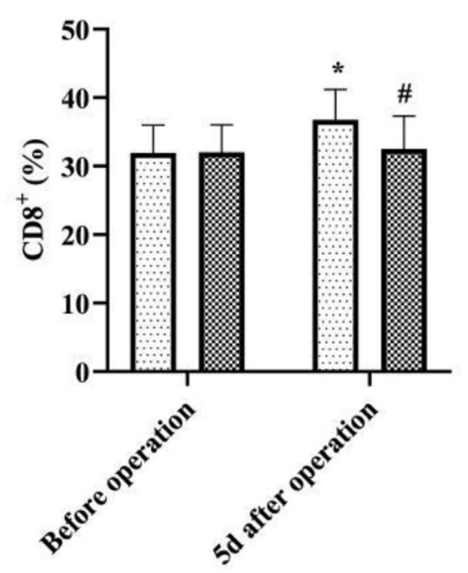

四 Allogeneic group

Autologous group

C

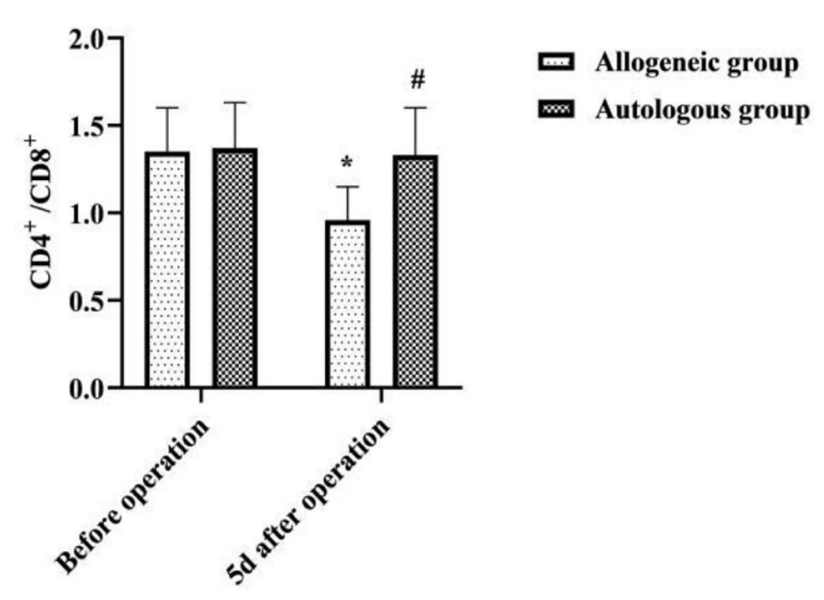

Allogeneic group

matologous group

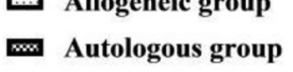

FIGURE 4 | Effect of different blood transfusion methods on patients' $T$-cell subsets. (A) CD4 ${ }^{+}$, (B) $C D 8^{+}$, and (C) $C D 4^{+} / \mathrm{CD} 8^{+}$. Compared with the same group before operation, ${ }^{*} P<0.05$; compared with allogeneic group $5 \mathrm{~d}$ after operation, ${ }^{\#} P<0.05$.

groups before transfusion and transfusion for $10 \min (P>0.05)$ (Figure 1).

\section{Effect of Different Blood Transfusion Methods on Patients' Blood Routine}

$5 \mathrm{~d}$ after operation, the RBC, PLT, HCT, and $\mathrm{Hb}$ of the allogeneic group were lower than those before operation, and the autologous group was higher than that of the allogeneic group $(P$ $<0.05$ ) (Figure 2).

\section{Effect of Different Blood Transfusion Methods on Patients' Inflammatory Factors} $5 \mathrm{~d}$ after operation, the CRP, TNF- $\alpha$, and IL- 6 of the allogeneic group were higher than those before operation, and the autologous group was lower than that of the allogeneic group $(P$ $<0.05$ ) (Figure 3).

\section{Effect of Different Blood Transfusion} Methods on Patients' T-Cell Subsets

$5 \mathrm{~d}$ after operation, the $\mathrm{CD} 4^{+}, \mathrm{CD} 4^{+} / \mathrm{CD}^{+}$of the allogeneic group were lower than before operation, and the $\mathrm{CD}^{+}$was higher than before operation. The $\mathrm{CD} 4^{+}$and $\mathrm{CD} 4^{+} / \mathrm{CD}^{+}$of the autologous group were higher than that of the allogeneic group, and $\mathrm{CD}_{8}{ }^{+}$was lower than that of the allogeneic group $(P<0.05)$ (Figure 4).

\section{Effect of Different Blood Transfusion Methods on Patients' Immunoglobulins}

$5 \mathrm{~d}$ after operation, the $\operatorname{IgA}, \operatorname{IgG}$, and $\operatorname{IgM}$ of the allogeneic group were lower than those before operation, and the autologous group was higher than that of the allogeneic group $(P<0.05)$ (Figure 5). 
A

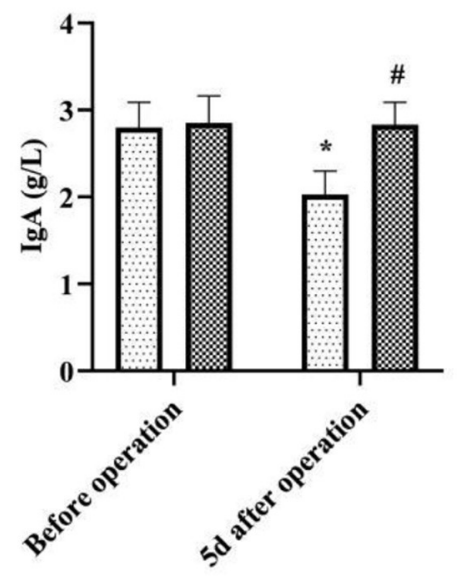

C

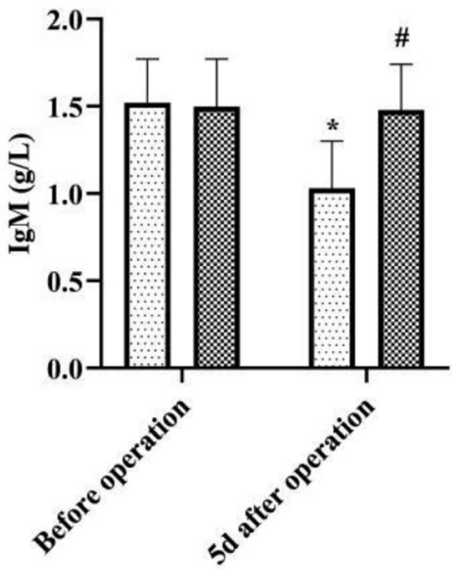

B

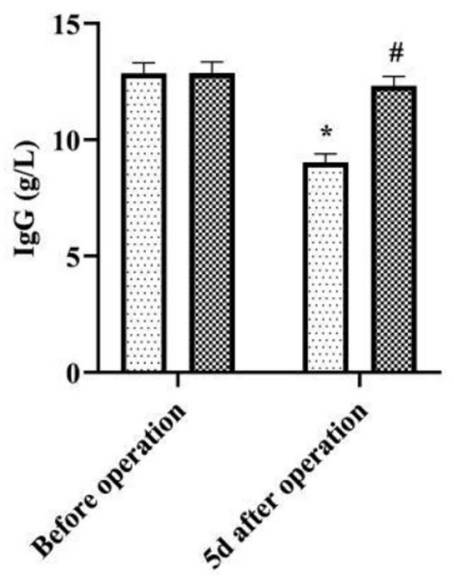

四 Allogeneic group

Autologous group

FIGURE 5 | Effect of different blood transfusion methods on patients' immunoglobulin's. (A) IgA, (B) IgG, and (C) IgM. Compared with the same group before operation, ${ }^{*} P<0.05$; compared with allogeneic group $5 \mathrm{~d}$ after operation, ${ }^{*} P<0.05$.

\section{Adverse Reaction Rate of Different Blood Transfusion Methods}

During blood transfusion, there was no significant difference in the adverse reaction rate between the two groups $(P>0.05)$ (Table 2).

\section{DISCUSSION}

In recent years, due to social factors such as late marriage and late childbirth, and second child policy, the number of advanced maternal age and scarred uterus re-pregnancy in China has been increasing, and the cesarean delivery rate has also increased, and in some areas it has exceeded 50\% (12). It is reported that cesarean section patients are prone to severe bleeding that is not easy to control during the perinatal period, which is one of the main reasons for the poor prognosis or even death of mothers and babies (13). So, timely, reasonable, and adequate blood transfusion treatment is of great significance for suppressing perinatal hemorrhage and ensuring the safety of mothers and babies. Allogeneic transfusion is the main method at present, but it has been plagued by problems such as tight blood source and many adverse reactions of blood transfusion. It has been reported that $\mathrm{ANH}$ autologous transfusion may be superior to allogeneic blood transfusion in terms of blood safety (14). However, this blood transfusion method uses exogenous fluid for dilution, and whether the blood transfusion will affect the vital signs, immune function, and inflammation levels of patients undergoing cesarean section is still unknown. This study provided a comparative analysis in this regard.

It has been suggested that blood volume increases in women after pregnancy and that ANH autologous transfusion can achieve a reduction in blood viscosity, increase blood oxygen uptake, reduce cardiac burden, and protect the myocardium through preoperative blood sampling and dilution (15). In this 
TABLE 2 | Adverse reaction rate of different blood transfusion methods ( $n$, \%).

\begin{tabular}{lccccc}
\hline Group & Allergy & Fever & Hemolysis & Others & Total \\
\hline Allogeneic group $(n=55)$ & $1(1.82)$ & $2(3.64)$ & $1(1.82)$ & $3(5.45)$ & $7(12.73)$ \\
Autosomal group $(n=55)$ & $1(1.82)$ & $1(1.82)$ & $0(0.00)$ & $2(3.64)$ & $4(7.28)$ \\
$\chi^{2}$ value & & & & & 0.909 \\
$P$ value & & & & & 0.340 \\
\hline
\end{tabular}

study, there was no statistical significance in the intra-group and inter-group comparisons of HR, MAP, and SVV between the two groups before transfusion and transfusion for $10 \mathrm{~min}(P$ $>0.05$ ). It showed that ANH autologous transfusion helps to maintain hemodynamic stability in patients undergoing cesarean section. To analyze the reasons, HES, as an artificial colloidal fluid with large molecular weight, has the pharmacological properties of being unable to penetrate the vessel wall, long intravascular retention time, and good effect of maintaining plasma colloidal osmotic pressure (16). Therefore, compared with isotonic crystalloids, it can achieve hemodynamic stability with less dosage and faster effect, and is one of the most commonly used resuscitation fluids in hemorrhagic shock. Surgery may result in loss of tangible components of blood, and allogeneic transfusions may result in destruction of blood components due to the long storage time of blood. In this study, $5 \mathrm{~d}$ after operation, the RBC, PLT, HCT, and $\mathrm{Hb}$ of the allogeneic group were lower than those before operation, and the autologous group was higher than that of the allogeneic group $(P<0.05)$. It was suggested that $\mathrm{ANH}$ autologous transfusion is an effective way to improve hematoprotection and prevent the development of postoperative anemia. Analyze the reasons. Compared with allogeneic blood transfusion, ANH autologous blood transfusion is performed by drawing autologous blood before surgery and returning it to the patient during surgery, which not only reduces the loss of red blood cells and platelets during surgery, but also has a short storage time and does not require refrigeration, so the blood components are less damaged, which facilitates the patient's postoperative recovery. CRP, TNF- $\alpha$, and IL- 6 are all key cytokines that initiate inflammatory or immune responses when the body perceives inflammatory stimuli such as trauma $(17,18)$. In this study, $5 \mathrm{~d}$ after operation, the CRP, TNF- $\alpha$, and IL- 6 of the allogeneic group were higher than those before operation, and the autologous group was lower than that of the allogeneic group $(P$ $<0.05)$. It was suggested that allogeneic transfusion can lead to varying degrees of inflammatory response in patients undergoing cesarean section, whereas ANH autologous transfusion has a mild effect on the level of inflammation in patients. This may be related to the fact that the blood dilution of $\mathrm{ANH}$ autotransfusion reduces concentrations of cortisol and catecholamines in plasma, and that the blood released out of the body after hemodilution is not involved in the acute phase response.

As an immunogenic and reactogenic substance, blood can be accompanied by a series of adverse reactions involving immune regulation in the process of blood transfusion therapy, mainly manifested as immunosuppression (19). Both T-cell subsets and immunoglobulins are important indicators to assess the immune function of the body, with the former playing a central regulatory role in cellular immunity and the latter being closely related to humoral immunity undertaken by $\mathrm{B}$ cells $(20,21)$. When allogeneic blood enters the human body as foreign protein antigen, the differentiation of $\mathrm{T}$ lymphocytes into $\mathrm{CD} 4^{+}$cells is inhibited, cytotoxic $\mathrm{T}$ lymphocytes $\left(\mathrm{CD} 8^{+}\right.$ $\mathrm{T}$ cells) are activated, and then the proportion of $\mathrm{CD} 4^{+} / \mathrm{CD}^{+}$ is unbalanced, resulting in abnormal immune function. In this study, $5 \mathrm{~d}$ after operation, the $\mathrm{CD} 4^{+}, \mathrm{CD} 4^{+} / \mathrm{CD} 8^{+}, \mathrm{IgA}, \mathrm{IgG}$ and IgM of the allogeneic group were lower than before operation, and the $\mathrm{CD}^{+}$was higher than before operation. The $\mathrm{CD} 4^{+}$, $\mathrm{CD} 4^{+} / \mathrm{CD}^{+}, \operatorname{IgA}, \operatorname{IgG}$ and $\operatorname{IgM}$ of the autologous group were higher than that of the allogeneic group, and $\mathrm{CD}^{+}$was lower than that of the allogeneic group $(P<0.05)$. It indicated that allogeneic transfusion can cause a decrease in immune function in the recipient, while $\mathrm{ANH}$ autologous transfusion has less effect on immune function in patients undergoing cesarean section. Analysis of the causes may be related to a decrease in the immune function of red blood cells due to the long storage time of the stock blood used for allogeneic transfusion. Numerous studies (22-24) have shown that the erythrocyte system has some immune functions that cannot be replaced by other immune cells, namely, reducing free radical damage, scavenging immune complexes, and participating in immune defense. Under normal circumstances, stock blood used for allogeneic transfusion can be stored at a constant temperature of $4^{\circ} \mathrm{C}$ for $2-3$ weeks. However, the longer the storage time, the more serious the deformation and aging of $\mathrm{RBCs}$, the gradual decrease of $\mathrm{RBC}-\mathrm{C} 3 \mathrm{~b}$ receptor activity, the excessive accumulation of related metabolites, the increase of immune complexes, and finally the impaired immune function of RBCs (25). In contrast, autologous blood of $\mathrm{ANH}$ autologous transfusion has a short retention time outside the body and does not require refrigeration, has few changes in red blood cells and their associated metabolites, and is free of alloantigens and proteins, and has few white blood cell fragments, thus causing minimal suppression of the immune system. The results of this study also showed that the incidence of adverse transfusion reactions such as allergy, fever, and hemolysis was slightly lower in the autologous group than in the allogeneic group $(P>0.05)$. It can be seen that ANH autologous transfusion is safer and will not increase the incidence of adverse blood transfusion reactions.

\section{CONCLUSION}

Through the comparative analysis of the above results, we found that both allogeneic and $\mathrm{ANH}$ autologous transfusion had little effect on the vital signs of patients undergoing cesarean section, but $\mathrm{ANH}$ autologous transfusion was more helpful in stabilizing the postoperative blood routine, $T$-cell subpopulation, immunoglobulin, and inflammation levels, and was a safe and effective way of blood transfusion. It is worth noting that although $\mathrm{ANH}$ autologous transfusion is a safe and effective way of blood transfusion, it can not completely replace allogeneic blood transfusion. Some studies 
(26) pointed out that when high-dose HES is used, due to the dilution effect, it may cause dose-related abnormal blood coagulation and decrease of HCT. Therefore, when the body has massive bleeding and the amount of recovered blood is also large, RBC, PLT and coagulation factors need to be supplemented at the same time in order to avoid serious coagulation dysfunction. The specific blood transfusion method should also depend on the specific situation of the patient.

\section{DATA AVAILABILITY STATEMENT}

The original contributions presented in the study are included in the article/supplementary material, further inquiries can be directed to the corresponding author/s.

\section{REFERENCES}

1. Yapca OE, Topdagi YE, Al RA. Fetus delivery time in extraperitoneal versus transperitoneal cesarean section: a randomized trial. J Matern Fetal Neonatal Med. (2020) 33:657-63. doi: 10.1080/14767058.2018.1499718

2. Zou YQ, Chen XX, Feng Y. Clinical study on perinatal outcomes of 80 cases with unicornuate uterus pregnancy. Zhonghua Fu Chan Ke Za Zhi. (2020) 55:510-5. doi: 10.3760/cma.j.cn112141-20200107-00019

3. Hulse W, Bahr TM, Morris DS, Richards DS, Ilstrup SJ, Christensen RD. Emergency-release blood transfusions after postpartum hemorrhage at the Intermountain Healthcare hospitals. Transfusion. (2020) 60:141823. doi: 10.1111/trf.15903

4. Lecarpentier E, Gris JC, Cochery-Nouvellon E, Mercier E, Abbas H, Thadhani R, et al. Urinary placental growth factor for prediction of placental adverse outcomes in high-risk pregnancies. Obstet Gynecol. (2019) 134:132632. doi: 10.1097/AOG.0000000000003547

5. Wright GP, Wolf AM, Waldherr TL, Ritz-Holland D, Laney ED, Chapman $\mathrm{HA}$, et al. Preoperative tranexamic acid does not reduce transfusion rates in major oncologic surgery: Results of a randomized, double-blind, and placebocontrolled trial. J Surg Oncol. (2020) 122:1037-42. doi: 10.1002/jso.26142

6. Terai A, Terada N, Yoshimura K, Ichioka K, Ueda N, Utsunomiya N, et al. Use of acute normovolemic hemodilution in patients undergoing radical prostatectomy. Urology. (2005) 65:1152-6. doi: 10.1016/j.urology.2004.12.034

7. Bennett J, Haynes S, Torella F, Grainger H, McCollum C. Acute normovolemic hemodilution in moderate blood loss surgery: a randomized controlled trial. Transfusion. (2006) 46:1097-103. doi: 10.1111/j.1537-2995.2006.00857.x

8. Iwase Y, Kohjitani A, Tohya A, Sugiyama K. Preoperative autologous blood donation and acute normovolemic hemodilution affect intraoperative blood loss during sagittal split ramus osteotomy. Transfus Apher Sci. (2012) 46:24551. doi: 10.1016/j.transci.2012.03.014

9. Oppitz PP, Stefani MA. Acute normovolemic hemodilution is safe in neurosurgery. World Neurosurg. (2010) 79:71924. doi: 10.1016/j.wneu.2012.02.041

10. Irlbeck T, Zwißler B, Bauer A. ASA-Klassifikation : Wandel im Laufe der Zeit und Darstellung in der Literatur [ASA classification : transition in the course of time and depiction in the literature]. Anaesthesist. (2017) 66:510. doi: 10.1007/s00101-016-0246-4

11. Akinlusi FM, Rabiu KA, Durojaiye IA, Adewunmi AA, Ottun TA, Oshodi YA. Cesarean delivery-related blood transfusion: correlates in a tertiary hospital in Southwest Nigeria. BMC Pregnancy Childbirth. (2018) 18:24. doi: 10.1186/s12884-017-1643-7

12. Su Y, Heitner J, Yuan C, Si Y, Wang D, Zhou Z, et al. Effect of a text messagingbased educational intervention on cesarean section rates among pregnant women in china: quasirandomized controlled trial. JMIR Mhealth Uhealth. (2020) 8:e19953. doi: 10.2196/19953

13. Khanal V, Karkee R, Lee AH, Binns CW. Adverse obstetric symptoms and rural-urban difference in cesarean delivery in Rupandehi

\section{ETHICS STATEMENT}

The studies involving human participants were reviewed and approved by the Ethics Committee of the First Affiliated Hospital of Naval Military Medical University. The patients/participants provided their written informed consent to participate in this study.

\section{AUTHOR CONTRIBUTIONS}

FG and HT are responsible for the design of the study and manuscript writing. XW is the instructor of the entire study, responsible for the inclusion of cases, and data statistics. All authors contributed to the article and approved the submitted version.

district, Western Nepal: a cohort study. Reprod Health. (2016) 13:17. doi: 10.1186/s12978-016-0128-x

14. Sarkanović ML, Gvozdenović L, Savić D, Ilić MP, Jovanović G. Autologous blood transfusion in total knee replacement surgery. Vojnosanit Pregl. (2013) 70:274-8. doi: 10.2298/VSP1303274L

15. van der Post JA, van Buul BJ, Hart AA, van Heerikhuize JJ, Pesman G, Legros JJ, et al. Vasopressin and oxytocin levels during normal pregnancy: effects of chronic dietary sodium restriction. J Endocrinol. (1997) 152:34554. doi: $10.1677 /$ joe. 0.1520345

16. Duncan AE, Jia Y, Soltesz E, Leung S, Yilmaz HO, Mao G, et al. Effect of $6 \%$ hydroxyethyl starch 130/0.4 on kidney and haemostatic function in cardiac surgical patients: a randomized controlled trial. Anaesthesia. (2020) 75:1180-90. doi: 10.1111/anae.14994

17. Li K, Xu Y, Hu Y, Liu Y, Chen X, Zhou Y. Effect of enteral immunonutrition on immune, inflammatory markers and nutritional status in gastric cancer patients undergoing gastrectomy: a randomized double-blinded controlled trial. J Invest Surg. (2020) 33:950-9. doi: 10.1080/08941939.2019.1569736

18. Nelson KA, Aldea GS, Warner P, Latchman Y, Gunasekera D, Tamir A, et al. Transfusion-related immunomodulation: gamma irradiation alters the effects of leukoreduction on alloimmunization. Transfusion. (2019) 59:3396404. doi: 10.1111/trf.15555

19. Arasaratnam RJ, Tzannou I, Gray T, Aguayo-Hiraldo PI, Kuvalekar M, Naik S, et al. Dynamics of virus-specific T cell immunity in pediatric liver transplant recipients. Am J Transplant. (2018) 18:2238-49. doi: 10.1111/ajt.14967

20. Longbrake EE, Mao-Draayer Y, Cascione M, Zielinski T, Bame E, Brassat D, et al. Dimethyl fumarate treatment shifts the immune environment toward an anti-inflammatory cell profile while maintaining protective humoral immunity. Mult Scler. (2021) 27:883-94. doi: 10.1177/1352458520937282

21. Li H, Zhang XS. Impacts of moxibustion on erythrocyte immune function and T-lymphocyte subsets in athletes. Zhongguo Zhen Jiu. (2013) 33:415-8.

22. Evers D, Middelburg RA, de Haas M, Zalpuri S, de Vooght KM, van de Kerkhof D, et al. Red-blood-cell alloimmunisation in relation to antigens' exposure and their immunogenicity: a cohort study. Lancet Haematol. (2016) 3:e284-92. doi: 10.1016/S2352-3026(16)30019-9

23. Wang S, Gao G, He Y, Li Q, Li Z, Tong G. Amidation-Modified Apelin-13 regulates ppar $\gamma$ and perilipin to inhibit adipogenic differentiation and promote lipolysis. Bioinorg Chem Appl. (2021) 2021:3594630. doi: $10.1155 / 2021 / 3594630$

24. Sparrow RL, Veale MF, Healey G, Payne KA. Red blood cell (RBC) age at collection and storage influences RBC membraneassociated carbohydrates and lectin binding. Transfusion. (2007) 47:966-8. doi: 10.1111/j.1537-2995.2007.01230.x

25. Chong Sung K, Kum Suk P, Mi Ja Y, Kyoung Ok K. Effects of intravascular volume therapy using hydroxyethyl starch (130/0.4) on post-operative bleeding and transfusion requirements in children undergoing cardiac surgery: a randomized clinical trial. Acta Anaesthesiol Scand. (2006) 50:10811. doi: 10.1111/j.1399-6576.2005.00881.x 
26. Porter Starr KN, Orenduff M, McDonald SR, Mulder H, Sloane R, Pieper $\mathrm{CF}$, et al. Influence of weight reduction and enhanced protein intake on biomarkers of inflammation in older adults with obesity. J Nutr Gerontol Geriatr. (2019) 38:33-49. doi: 10.1080/21551197.2018.1564200

Conflict of Interest: The authors declare that the research was conducted in the absence of any commercial or financial relationships that could be construed as a potential conflict of interest.

Publisher's Note: All claims expressed in this article are solely those of the authors and do not necessarily represent those of their affiliated organizations, or those of the publisher, the editors and the reviewers. Any product that may be evaluated in this article, or claim that may be made by its manufacturer, is not guaranteed or endorsed by the publisher.

Copyright (c) 2022 Guo, Tang and Wei. This is an open-access article distributed under the terms of the Creative Commons Attribution License (CC BY). The use, distribution or reproduction in other forums is permitted, provided the original author(s) and the copyright owner(s) are credited and that the original publication in this journal is cited, in accordance with accepted academic practice. No use, distribution or reproduction is permitted which does not comply with these terms. 